\title{
A facile preparation of FePt-loaded few-layer $\mathrm{MoS}_{2}$ nanosheets nanocomposites (F-MoS $2-\mathrm{FePt}$ $\mathrm{NCs}$ ) and their application for colorimetric detection of $\mathrm{H}_{2} \mathrm{O}_{2}$ in living cells
}

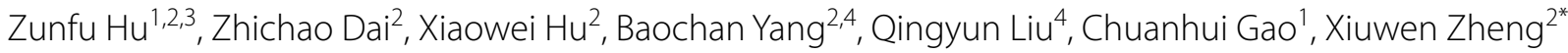 \\ and Yueqin $\mathrm{Yu}^{1 *}$
}

\begin{abstract}
Background: Rapid and sensitive detection of $\mathrm{H}_{2} \mathrm{O}_{2}$ especially endogenous $\mathrm{H}_{2} \mathrm{O}_{2}$ is of great importance for series of industries including disease diagnosis and therapy. In this work, uniform FePt nanoparticles are successfully anchored onto Few-layer molybdenum disulfide nanosheets ( $\left.-\mathrm{MoS}_{2} \mathrm{NSs}\right)$. The powder X-ray diffraction, transmission electron microscopy, UV-Vis spectra and atomic force microscopy were employed to confirm the structure of the obtained nanocomposites (F-MoS 2 -FePt NCs). The prepared nanocomposites show efficient peroxidase-like catalytic activities verified by catalyzing the peroxidation substrate 4,4'-diamino-3,3',5,5'-tetramethylbiphenyl (TMB) with the existence of $\mathrm{H}_{2} \mathrm{O}_{2}$.
\end{abstract}

Results: The optimal conditions of the constructed colorimetric sensing platform is proved as $35^{\circ} \mathrm{C}$ and $\mathrm{pH} 4.2$. Under optimal catalytic conditions, the detection limit for $\mathrm{H}_{2} \mathrm{O}_{2}$ detection reaches $2.24 \mu \mathrm{M}$ and the linear ranger is $8 \mu \mathrm{M}$ to $300 \mu \mathrm{M}$. Furthermore, the proposed colorimetric sensing platform was successfully utilized to detect the intracellular $\mathrm{H}_{2} \mathrm{O}_{2}$ of cancer cells (MCF-7).

Conclusions: These findings indicated that the $\mathrm{F}-\mathrm{MoS}_{2}-\mathrm{FePt}-\mathrm{TMB}-\mathrm{H}_{2} \mathrm{O}_{2}$ system provides a potential sensing platform for hydrogen peroxide monitoring in living cells.

Keywords: Few-layer $\mathrm{MoS}_{2}$ nanosheets, FePt, Colorimetric, $\mathrm{H}_{2} \mathrm{O}_{2}$, Intracellular $\mathrm{H}_{2} \mathrm{O}_{2}$

\section{Background}

Hydrogen peroxide $\left(\mathrm{H}_{2} \mathrm{O}_{2}\right)$ takes an essential position in many biochemical reactions, such as metabolism of proteins and carbohydrates. Furthermore, it can be used as a significant indicator of the occurrence of many serious disease especially cancer $[1,2]$. Consequently, a sensitive, cost-effective, rapid and easy operation method for $\mathrm{H}_{2} \mathrm{O}_{2}$ determination would be demanded for bioassays and environmental applications [3]. Up to now, several

\footnotetext{
*Correspondence: zhengxiuwen@lyu.edu.cn; qustyu@163.com

${ }^{1}$ Collage of Chemistry and Molecular Engineering, Qingdao University

of Science and Technology, Qingdao, China

${ }^{2}$ Key Laboratory of Functional Nanomaterials and Technology

in Universities of Shandong, Linyi University, Linyi, China

Full list of author information is available at the end of the article
}

techniques for $\mathrm{H}_{2} \mathrm{O}_{2}$ determination, such as chromatography [4], chemiluminescence, electrochemistry [5, 6] and colorimetric method [7], have been reported. Among these techniques, colorimetric route has several outstanding advantages, including visibility, low cost, easy automation, portability and operation convenience [8]. Although enormous progresses have been made, sensitive and rapid detection of $\mathrm{H}_{2} \mathrm{O}_{2}$ still remains highly need. Recently, due to its high selectivity, many nanometerials were employed to construct colorimetric sensors to detect $\mathrm{H}_{2} \mathrm{O}_{2}$.

Conventional enzymes are especially effective when catalyze series of reactions under mild conditions. However, conventional enzymes have rigorous limitations in practical use because they usually show insufficient 
stability in cruel conditions, additionally, they are hard to purify and preserve [9]. Therefore, over the past few decades, an explosion of interests have been drawn to study enzyme-mimic materials aiming to get high efficiency without the mentioned shortcomings. To date, versatile nanomaterials, such as $\mathrm{CoS}$ NPs [10], $\mathrm{Fe}_{3} \mathrm{O}_{4}$ NPs [11, 12], Copper nanoclusters [7], metal-organic framework [13], $\mathrm{WS}_{2}$ nanosheets [14], graphene oxide [15, 16], and kinds of metals $[5,17,18]$ are used to fabricate nano-enzymes and exhibit effective catalytic activities suggesting prospective potentials in numerous bio-field, accompanied by series of advantages, including cost-effective, simple process, readily available raw materials, easy purification of products, low cost and long guarantee period [19, 20].

Molybdenum disulfide $\left(\mathrm{MoS}_{2}\right)$, with a graphene-like lamellar structure, is composed of $\mathrm{S}-\mathrm{Mo}-\mathrm{S}$ sandwich structure and held by weak van der Waals forces. The few-layer $\mathrm{MoS}_{2}$ nanosheets (F-MoS $2 \mathrm{NSs}$ ) with excellent 2D structure possess a direct bandgap of $1.8 \mathrm{eV}$, which is much higher than the indirect bandgap in bulk $\mathrm{MoS}_{2} \mathrm{NSs}$ $(1.2 \mathrm{eV})$ [21]. Hence, great efforts have been devoted to prepare few-layer $\mathrm{MoS}_{2} \mathrm{NSs}$ and they are applied in sensing, catalysis, supercapacitors and so on [22-27]. Furthermore, based on its super-large specific surface areas and abundant active edges, $\mathrm{MoS}_{2}$ NSs have been utilized as base material to integrate with series of nanomaterials to further improve their catalytic performance [28].
A variety of monometallic nanoparticles (MNPs), such as $\mathrm{Ag}[29,30], \mathrm{Pd}[31], \mathrm{Pt}[27], \mathrm{Au}[32,33]$ and Co NPs [34] have been successfully decorated on $2 \mathrm{D} \mathrm{MoS}_{2}$ NSs. The obtained $\mathrm{MoS}_{2}$-MNPs can enhance their intrinsic properties. However, it is extremely difficult to further enhance the catalytic efficiency. Therefore, bimetallic nanoparticles (BNPs) were developed to improve the catalytic abilities [35-41].

Platinum-based BNPs have been widely used as sensing materials in non-enzymatic $\mathrm{H}_{2} \mathrm{O}_{2}$ sensing platforms and they show excellent electronic and catalytic properties. Until now, few attempts have been made to study the peroxidase-like catalytic ability of FePt NPs. Therefore, both $\mathrm{MoS}_{2}$ and FePt NPs are expected to be employed together for the development of colorimetric sensor for $\mathrm{H}_{2} \mathrm{O}_{2}$ detection. In this work, few-layer $\mathrm{MoS}_{2} \mathrm{NSs}$ $\left(\mathrm{F}-\mathrm{MoS}_{2}\right)$ loaded uniformly FePt NPs are prepared and the catalytic activity of the obtained NCs are systematically studied. Scheme 1 illustrates the technical route to prepare the NCs and the method to detect $\mathrm{H}_{2} \mathrm{O}_{2}$.

\section{Results and discussion \\ Characterization of FePt nanoparticles, F-MoS 2 NSs and F-MoS 2 -FePt NCs}

The way to prepare $\mathrm{F}-\mathrm{MoS}_{2}-\mathrm{FePt} \mathrm{NCs}$ is depicted in Scheme 1, while the experiments details are described in the experimental section. In this work, few-layer $\mathrm{MoS}_{2}$

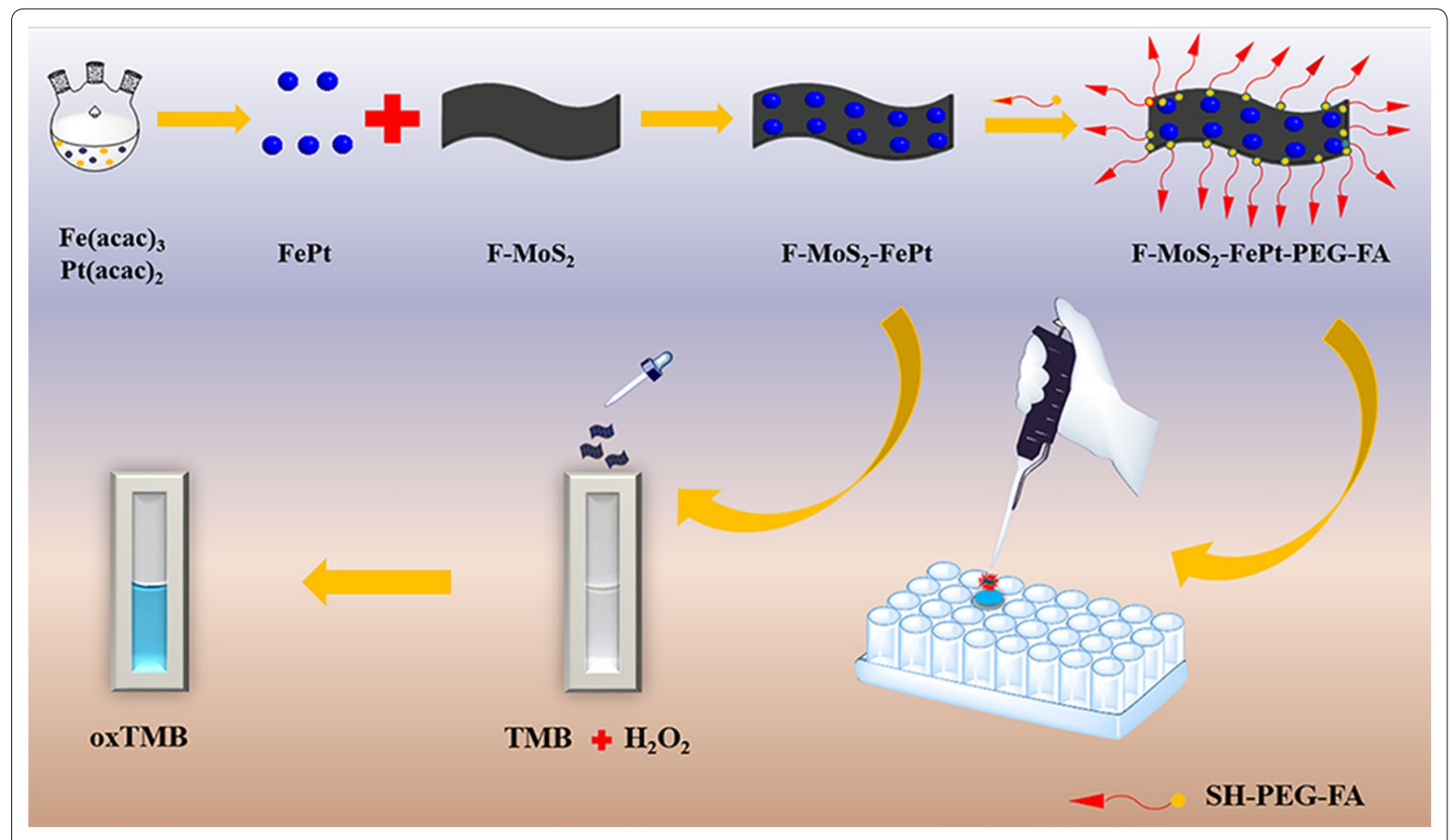

Scheme 1 Synthesis of few-layer $\mathrm{MoS}_{2}$-FePt and schematic representation of the prepared colorimetric sensing platform for $\mathrm{H}_{2} \mathrm{O}_{2}$ detection in vivo 
NSs $\left(\mathrm{F}-\mathrm{MoS}_{2}\right)$ are obtained by exfoliating bulk $\mathrm{MoS}_{2}$ via lithium intercalation-exfoliation. To investigate the thickness of the as-prepared $\mathrm{MoS}_{2}$ NSs, atomic force microscopy (AFM) is utilized to measure as-prepared $\mathrm{MoS}_{2}$ NSs. As shown in Additional file 1: Figure S1, the altitude of as-prepared $\mathrm{MoS}_{2} \mathrm{NSs}$ is around $2 \mathrm{~nm}$, implying as-prepared $\mathrm{MoS}_{2}$ NSs have 2-3 layers [25, 42].

Then TEM is employed to characterize the obtained nanomaterials. As illustrated in Fig. 1A, FePt NPs show uniform spherical morphology and the diameter is $4 \mathrm{~nm}$. The lattice fringes of as-prepared FePt NPs can be seen obviously in Fig. 1B, the adjacent fringe spacing is about $0.224 \mathrm{~nm}$, corresponding to the (111) lattice planes of FePt $[43,44]$. To equally disperse FePt NPs on the surface of $\mathrm{F}-\mathrm{MoS}_{2}$ NSs, the obtained FePt NPs are firstly transformed from the organic phase to aqueous phase via ligand exchange. The zeta potential of FePt-DMSA is $-25 \mathrm{mV}$, indicating the successful modification of FePt NPs by dimercaptosuccinic acid (DMSA) (Additional file 1: Figure S2). After modified with DMSA, FePt NPs can be well-dispersed in water. Then, the thiolated FePt NPs could be easily anchored on the defect-rich edge sites of F- $\mathrm{MoS}_{2}$ NSs. As shown in Fig. 1C, FePt NPs are successfully anchored onto the surface of F-MoS $\mathrm{NSs}_{2}$. Bulk $\mathrm{MoS}_{2}$ NSs are thicker and more visible than the exfoliated F- $\mathrm{MoS}_{2} \mathrm{NSs}$, as shown in Additional file 1: Figure S3. The lattice fringe spacing of the loaded nanoparticles is also $0.224 \mathrm{~nm}$, similar to the monodispersed FePt NPs, as illustrated in Fig. 1D.

Powder X-ray diffraction is utilized to further confirm the crystalline structure of as-prepared $\mathrm{F}-\mathrm{MoS}_{2} \mathrm{NSs}$, FePt NPs and F-MoS ${ }_{2}$-FePt NCs. The data of X-ray diffraction are displayed in Fig. 2a. The exfoliated F-MoS NSs exhibit series of highlighted peaks in accordance with the reported ultrathin $\mathrm{MoS}_{2}$ nanosheets [33]. The XRD spectra of FePt NPs show four peaks in accordance with the reported FePt NPs [45]. Nearly all peaks of FePt NPs and F-MoS ${ }_{2}$ NSs are found in the XRD patterns of F-MoS ${ }_{2}-\mathrm{FePt} \mathrm{NCs}$, shown in Fig. 2a. All data show that $\mathrm{F}-\mathrm{MoS}_{2}$-FePt NCs are successfully prepared.
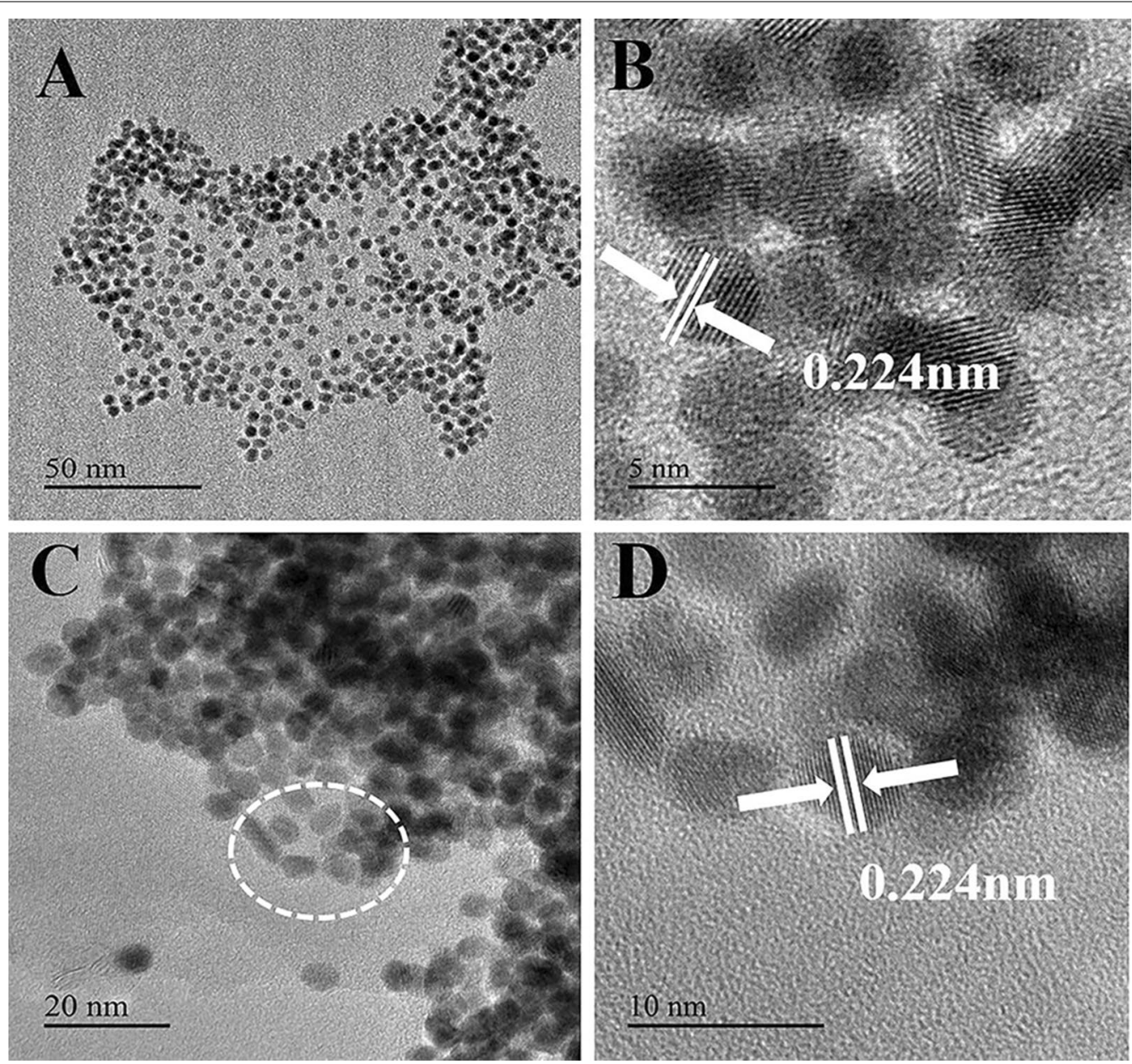

Fig. 1 TEM image of FePt NPs (A), HRTEM image of FePt NPs (B), TEM image of F-MoS 2 -FePt (C) and HRTEM image of F-MoS 2 -FePt (D) 

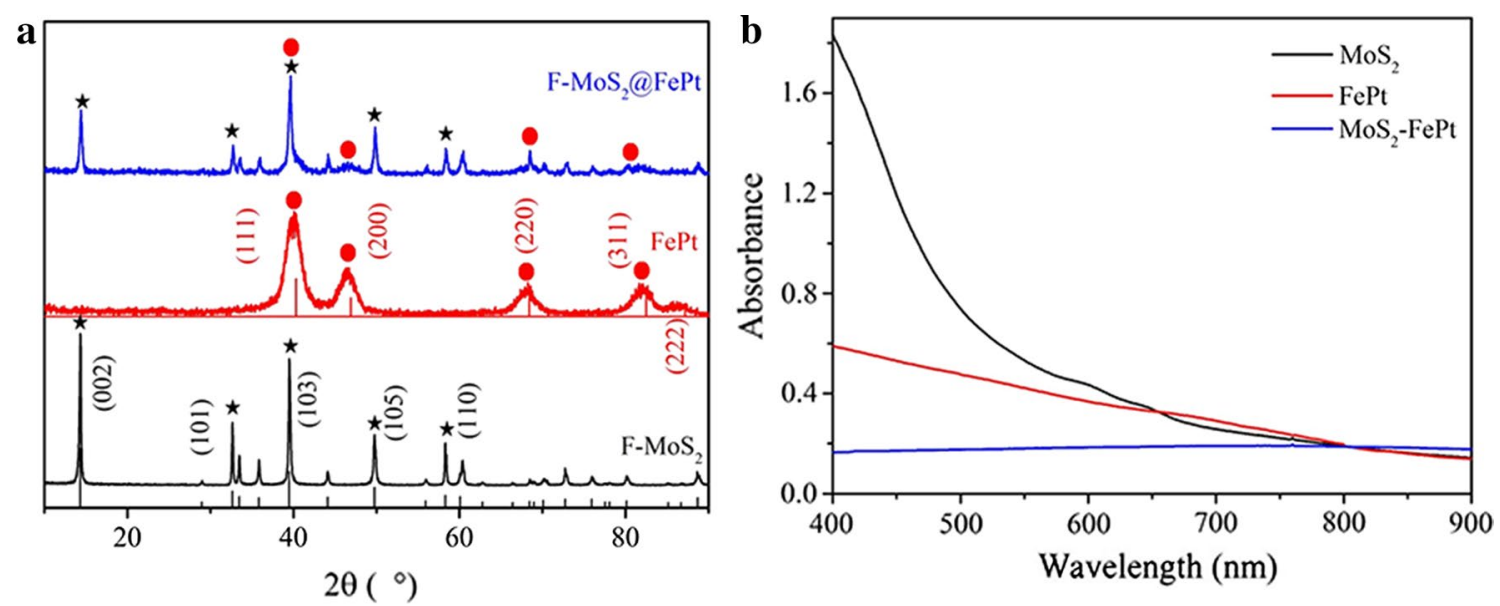

Fig. 2 a XRD patterns of $\mathrm{MoS}_{2}$ (black line), FePt (red line) and F-MoS 2 -FePt NCs (blue line). b UV-Vis spectra of MoS, (black line), FePt (red line) and

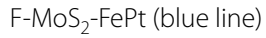

Furthermore, UV-Vis spectra are employed to characterize the obtained nanomaterials. As presented in Fig. 2b, after modified with FePt NPs, the strong absorbance of the exfoliated F-MoS 2 NSs is covered by sufficient FePt NPs, which show no obvious absorbance band from 400 to $900 \mathrm{~nm}$. These results demonstrate that FePt NPs is successfully anchored on the surface of F-MoS ${ }_{2}$ NSs.

\section{Peroxidase-like activity of the obtained FePt, F-MoS 2 NSs and $\mathrm{F}-\mathrm{MoS}_{2}$-FePt NCs}

To investigate the peroxidase-like catalytic activities of $\mathrm{F}-\mathrm{MoS}_{2}$-FePt NCs, 4,4'-diamino-3,3',5,5'tetramethylbiphenyl (TMB) is selected as chromogenic substrate to induce the color reaction. As depicted in Fig. $3 \mathrm{~A}$, a prominent absorption peak of the oxidation products at $652 \mathrm{~nm}$ is observed, while the other three systems do not have any well-developed peaks ranging from 400 to $800 \mathrm{~nm}$. As shown in the inset of Fig. 3A, in the presence of F-MoS $-\mathrm{FePt} \mathrm{NCs}$ and $\mathrm{H}_{2} \mathrm{O}_{2}$, the TMB solution turns blue promptly. However, the TMB solution remains colorless in the absence of either $\mathrm{H}_{2} \mathrm{O}_{2}$ or F- $\mathrm{MoS}_{2}$-FePt NCs. As illustrated in Fig. 3B, the absorbance of $\mathrm{F}-\mathrm{MoS}_{2}-\mathrm{FePt} / \mathrm{TMB} / \mathrm{H}_{2} \mathrm{O}_{2}$ at $652 \mathrm{~nm}$ climbs rapidly and maintains constantly within $100 \mathrm{~s}$, indicating $\mathrm{TMB}$ could be oxidized rapidly, while the absorbance of the reference experiment remains unchanged. The results prove that the obtained $\mathrm{F}-\mathrm{MoS}_{2}$ - $\mathrm{FePt} \mathrm{NCs}$ possess efficient peroxidase-like catalytic activity.

UV spectrum is utilized to estimate the catalytic activities of F-MoS - FePt NCs, bulk $\mathrm{MoS}_{2} \mathrm{NSs}, \mathrm{F}-\mathrm{MoS}_{2} \mathrm{NSs}$ and FePt NPs. As illustrated in Fig. 3C, the absorbance of $\mathrm{F}-\mathrm{MoS}_{2}$ - FePt NCs reaches the highest value among all the materials. Moreover, the absorbance of $\mathrm{F}-\mathrm{MoS}_{2} \mathrm{NSs}$ is much higher than bulk $\mathrm{MoS}_{2}$ NSs, which is attributed to the higher specific surface area and more exposed active sites. Furthermore, the time-dependent mode of the UV-Vis spectra at $652 \mathrm{~nm}$ for these materials is also investigated. As depicted in Fig. 3D, the UV spectra of $\mathrm{F}-\mathrm{MoS}_{2}-\mathrm{FePt} \mathrm{NCs}$ at $652 \mathrm{~nm}$ reach the balance within $100 \mathrm{~s}$ and the highest value is obtained, which indicates the strong synergistic effect between $\mathrm{F}-\mathrm{MoS}_{2} \mathrm{NSs}$ and FePt NPs [46].

Similar to other enzyme-mimic systems, temperature and $\mathrm{pH}$ play vital roles in the catalytic activities of F-MoS ${ }_{2}$-FePt NCs. As depicted in Fig. 4a, the absorption at $652 \mathrm{~nm}$ keeps relatively high between 20 and $50{ }^{\circ} \mathrm{C}$ and reaches the maximum value at about $40{ }^{\circ} \mathrm{C}$. Similarly, the influence of the $\mathrm{pH}$ of the TMB solution is also investigated as the $\mathrm{pH}$ varies from 2.2 to 8 . As depicted in Fig. 4b, higher UV-Vis absorption is acquired when the TMB solution is kept weakly acidic, which indicates that the weakly acidic environment would be beneficial to the oxidation of TMB. However, when the solution is kept neutral or basic, the UV-Vis absorption is relatively low, which is mainly attributed to the reason that under basic solution, more $\mathrm{OH}^{-}$groups are absorbed on F-MoS $2_{2}^{-}$ FePt NCs, occupying active sites of F- $\mathrm{MoS}_{2}-\mathrm{FePt} \mathrm{NCs} \mathrm{for}$ the further reaction with $\mathrm{H}_{2} \mathrm{O}_{2}$ [47]. In summary, $35{ }^{\circ} \mathrm{C}$ and weakly acidic condition $(\mathrm{pH}=4.2)$ are chosen as the optimum conditions.

\section{Kinetic investigation of $\mathrm{F}-\mathrm{MoS}_{2}-\mathrm{FePt} \mathrm{NCs}$ as peroxidase mimics}

Under optimal conditions, TMB and $\mathrm{H}_{2} \mathrm{O}_{2}$ are chosen as the substrates to study the steady-state kinetic of the prepared F-MoS ${ }_{2}$-FePt NCs. As illustrated in Fig. 5a, b, when TMB or $\mathrm{H}_{2} \mathrm{O}_{2}$ is catalyzed in certain concentration range, normative Michaels-Menten curves are acquired. 
A

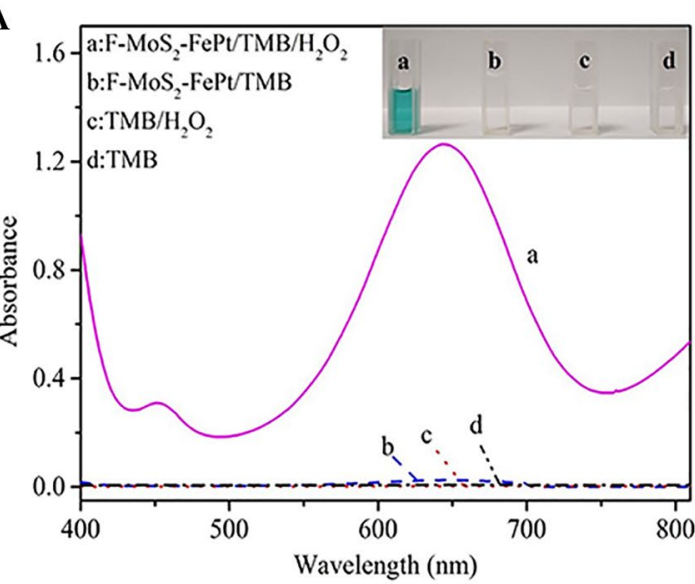

C

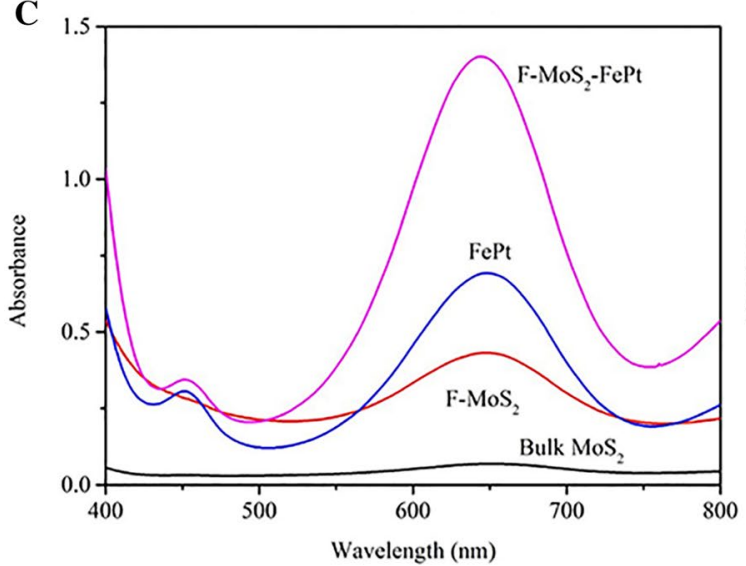

B

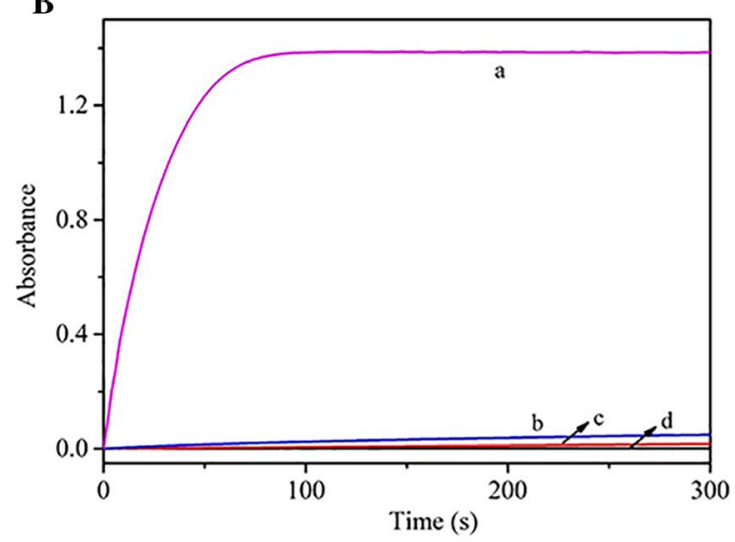

D

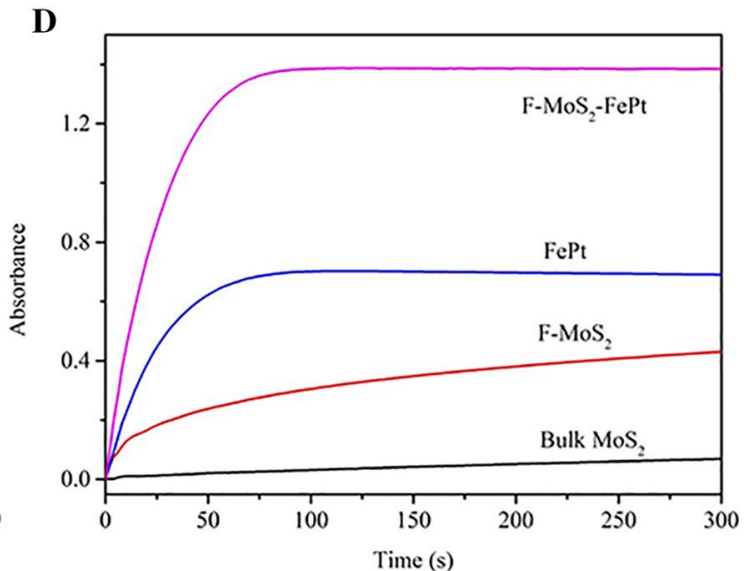

Fig. 3 A The investigation of peroxidase-like activity. (a) F-MoS 2 -FePt NCs $/ \mathrm{H}_{2} \mathrm{O}_{2} / T M B$; (b) F-MoS 2 -FePt NCs/TMB; (c) $\mathrm{H}_{2} \mathrm{O}_{2} / T M B$; (d) TMB. B Time-dependent ultraviolet absorbance changes at $652 \mathrm{~nm}$ of these experiments. CThe UV-Vis spectra of these obtained nano-enzymes. D Time-dependent ultraviolet absorbance changes at $652 \mathrm{~nm}$ of these obtained nano-enzymes
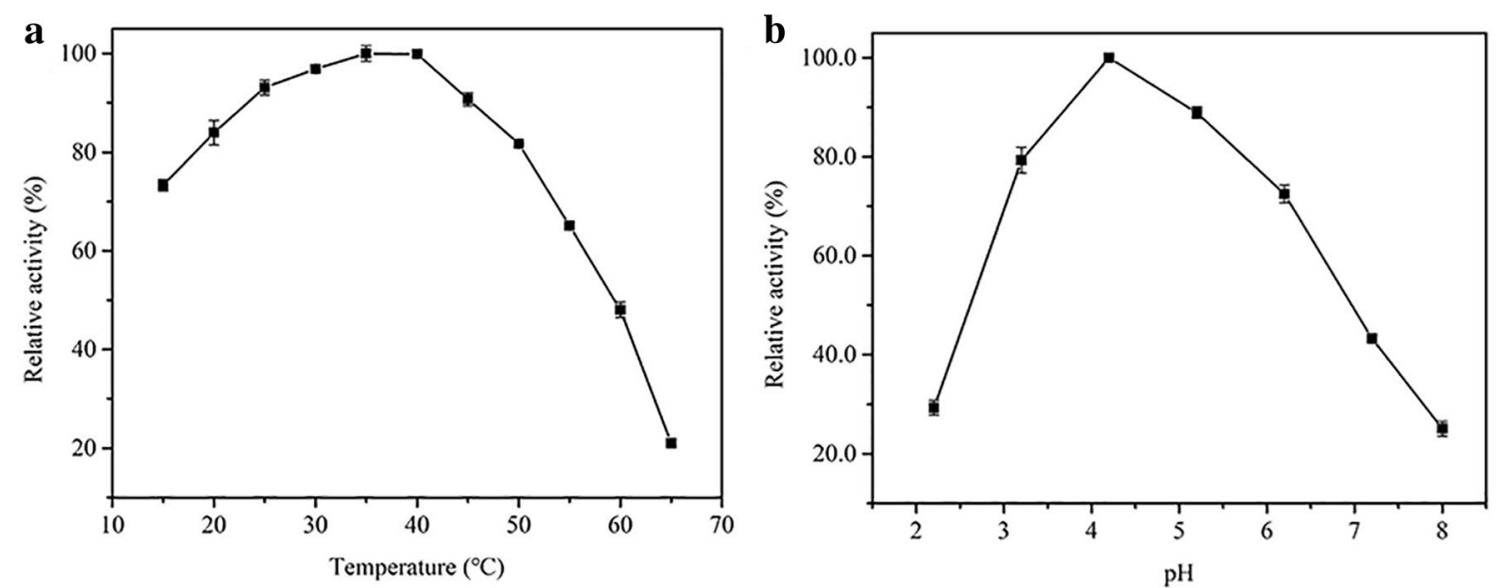

Fig. 4 The effects of temperature (a) and $\mathrm{pH}$ (b) on the catalytic activity of F-MoS 2 -FePt NCs. The reaction conditions are shown as follows: $1.4 \mathrm{~mL}$ CPBS (pH 4.2), $200 \mu \mathrm{L} \mathrm{TMB} \mathrm{(1} \mathrm{mM),} 200 \mu \mathrm{L}$ F-MoS 2 -FePt HNPs $\left(20 \mu \mathrm{L} \mathrm{mL}{ }^{-1}\right)$ and $200 \mu \mathrm{L} \mathrm{H}_{2} \mathrm{O}_{2}(0.25 \mathrm{M})$, the pH of the solution varies from 2.2 to 8

Michaels-Menten constant $\left(K_{\mathrm{m}}\right)$, which represents the affinity between substrates and catalyst, and the initial reaction velocity $\left(V_{\max }\right)$ are reckoned from the L-B plot, the results are displayed in Fig. $5 \mathrm{c}$, d. Based on the calculation, for the obtained F-MoS 2 -FePt NCs, the $K_{\mathrm{m}}$ value is $0.2225 \mathrm{mM}$ and the relevant $V_{\max }$ is $2.9458 \times 10^{-8} \mathrm{M} \mathrm{s}^{-1}$. 

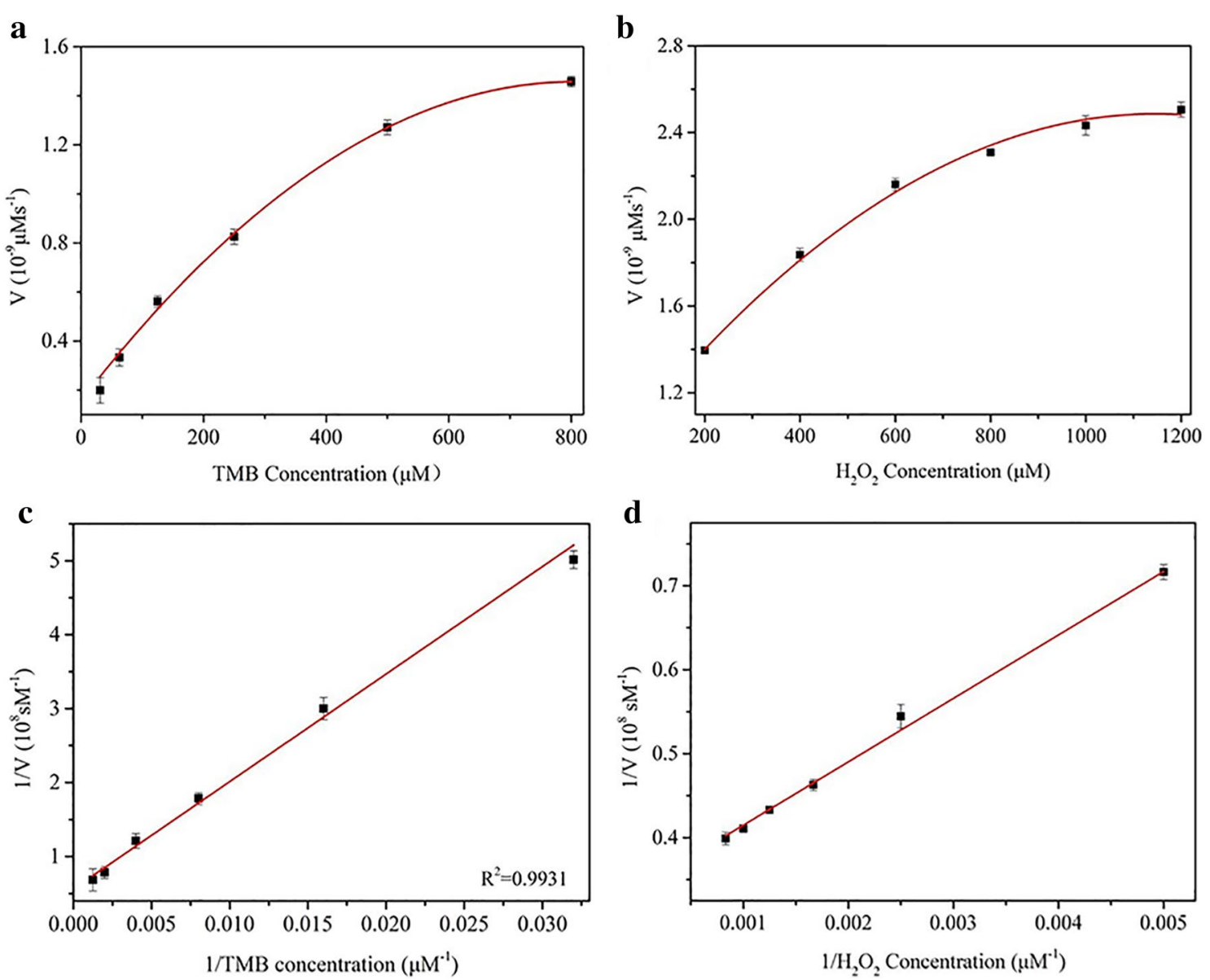

Fig. 5 Kinetic curves of F-MoS 2 -FePt NCs. The concentration of TMB (a) and $\mathrm{H}_{2} \mathrm{O}_{2}$ (b) are varied. Double reciprocal plots F-MoS 2 -FePt NCs by changing the concentration of TMB (c) and $\mathrm{H}_{2} \mathrm{O}_{2}$ (d)

Correspondingly, the $K_{\mathrm{m}}$ and $V_{\max }$ values with TMB are $0.4283 \mathrm{mM}$ and $1.7857 \times 10^{-8} \mathrm{M} \mathrm{s}^{-1}$. Compared with other reported artificial enzymes and Horseradish peroxidase, the $K_{\mathrm{m}}$ and $V_{\max }$ are much smaller, which represents higher affinity between $\mathrm{F}-\mathrm{MoS}_{2}$-FePt NCs and the substrates $\left(\mathrm{H}_{2} \mathrm{O}_{2}\right.$ and TMB $)[40,48-50]$.

\section{Catalytic mechanism}

Based on the prominent advantages such as cost-effective and high stability, p-Phthalic acid (TA) is applied to detect hydroxyl radicals $(\mathrm{OH} \cdot)$ produced by the decomposition of $\mathrm{H}_{2} \mathrm{O}_{2}$. Fluorescence spectrometer is carried out to monitor the production generated from the combination of TA and hydroxide radical. As displayed in Fig. 6, as the amount of F-MoS - -FePt NCs varies from 10 to $50 \mu \mathrm{g} \mathrm{mL}{ }^{-1}$, the fluorescence intensity decreases monotonically, which is caused by the reduction of hydroxide radical inhibited by high concentration of F- $\mathrm{MoS}_{2}$-FePt NCs. According to the literatures, electron transfer mechanism is applied to explain these catalytic activities, as shows in Fig. 7 [51-53]. F- $\mathrm{MoS}_{2}$-FePt NCs facilitate electrons shift between $\mathrm{H}_{2} \mathrm{O}_{2}$ and TMB. TMB can be easily absorbed on $\mathrm{F}-\mathrm{MoS}_{2}$-FePt NCs, this is because the higher affinity $\left(K_{\mathrm{m}}=0.4283\right)$ and donated lone-pair electrons from the amino groups cause the increase of the electron density and mobility on the NCs, as a result, the electron transfer to $\mathrm{H}_{2} \mathrm{O}_{2}$ is facilitated and the oxidation of TMB is speed up [54].

\section{Detection of $\mathrm{H}_{2} \mathrm{O}_{2}$ and sensing of the intracellular $\mathrm{H}_{2} \mathrm{O}_{2}$}

The determination of $\mathrm{H}_{2} \mathrm{O}_{2}$ is carried out under the optimal conditions using $\mathrm{UV}-\mathrm{Vis}$ absorption spectra ranging from $250 \mathrm{~nm}$ to $800 \mathrm{~nm}$. As illustrated in Fig. 8a, with the increasing of $\mathrm{H}_{2} \mathrm{O}_{2}$ the UV absorption at $652 \mathrm{~nm}$ of the colorimetric system increases gradually. More importantly, the absorbance is in proportion to $\mathrm{H}_{2} \mathrm{O}_{2}$ concentration, providing a linear detection range from 8 to $300 \mu \mathrm{M}$ (Fig. 8b). The corresponding image of the linear detection range of $\mathrm{H}_{2} \mathrm{O}_{2}$ is shown in the inset of Fig. 8a, which indicates that as the concentration decreases from 

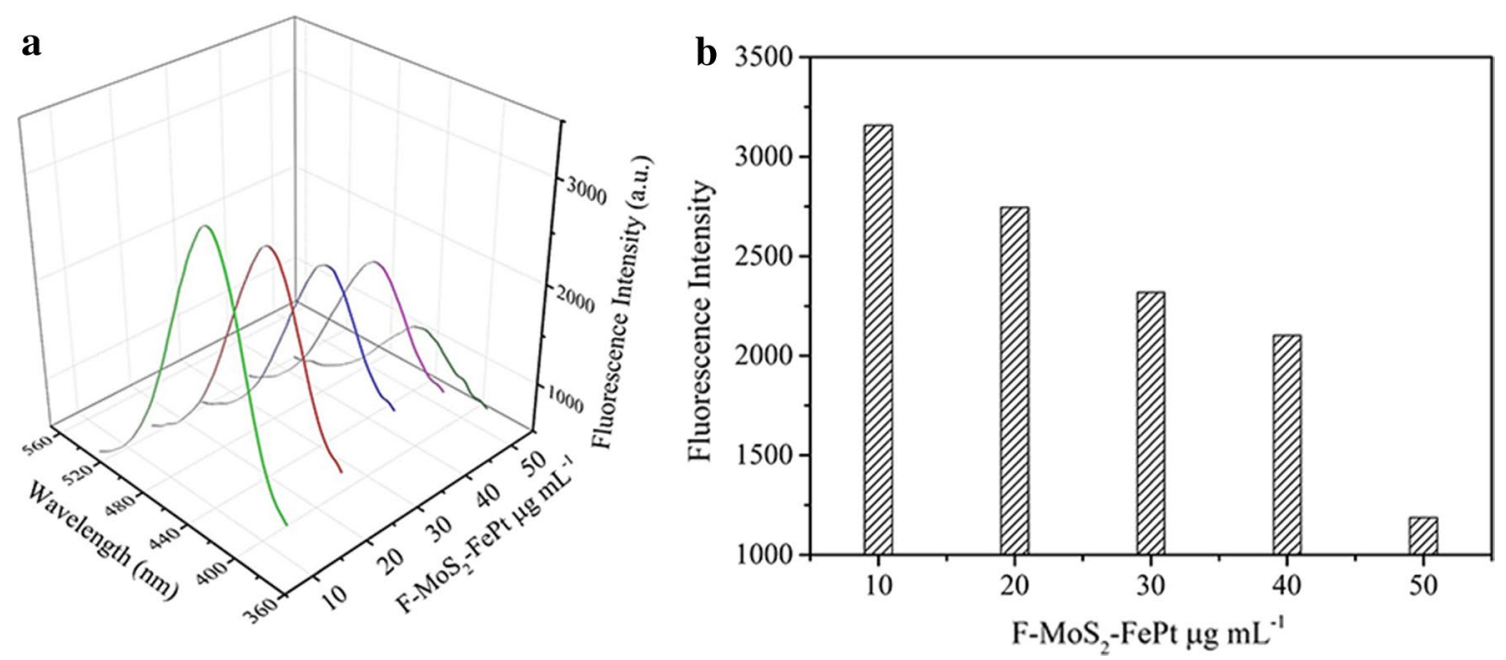

Fig. 6 a Emission spectra of the $p$-Phthalic acid with series of different amount of F-MoS $-\mathrm{FePt} \mathrm{NCs}$ and constant concentration of $\mathrm{H}_{2} \mathrm{O}_{2}$. The reaction conditions are shown as follows: $5 \mathrm{mM} \mathrm{TA}, 0.25 \mathrm{M} \mathrm{H}_{2} \mathrm{O}_{2}$, along with different amount of F-MoS $\mathrm{S}_{2}$-FePt NCs. b The corresponding fluorescence intensity of different amount of F-MoS $2-\mathrm{FePt} \mathrm{NCs}$

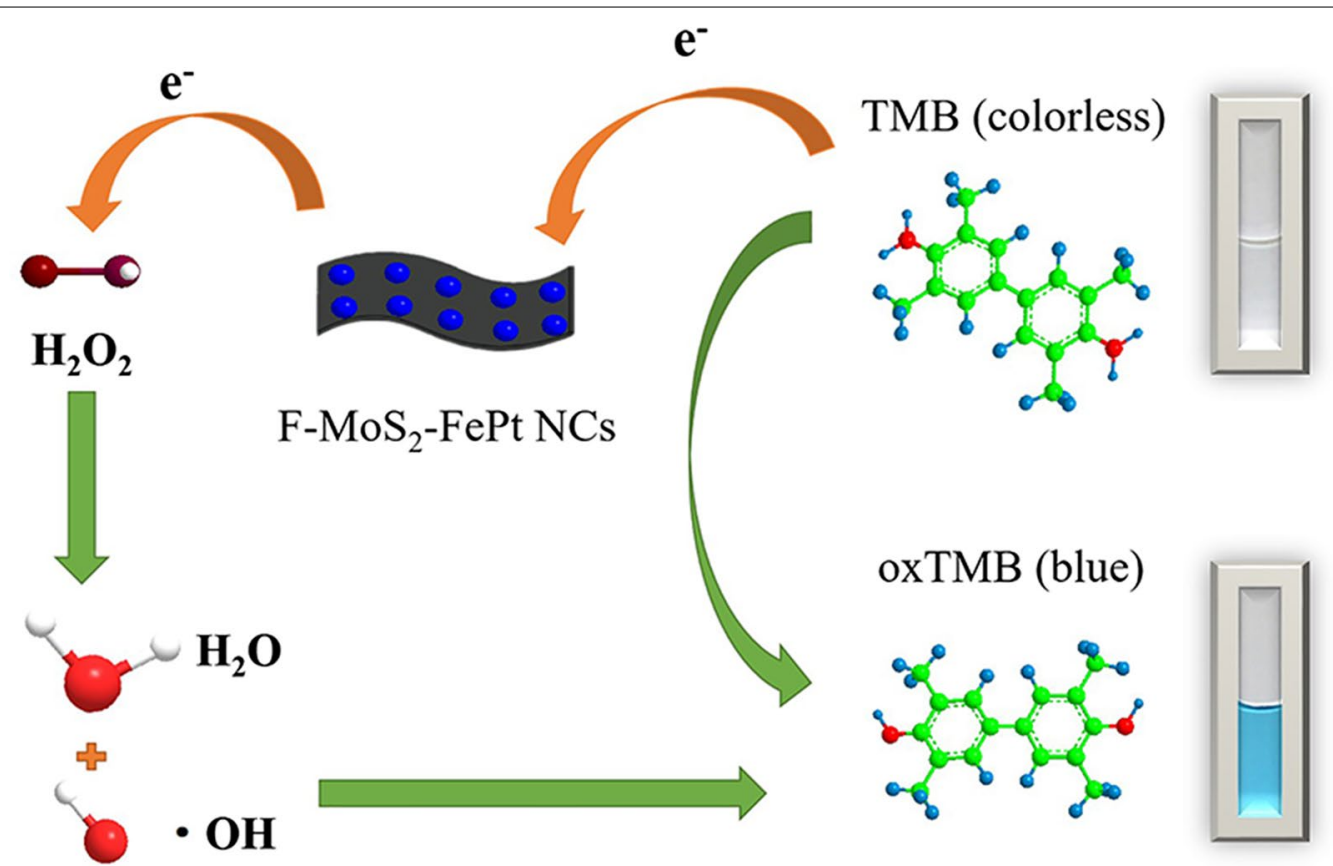

Fig. 7 The catalytic mechanism of the constructed F-MoS $2-F e P t-T M B-H_{2} \mathrm{O}_{2}$ colorimetric sensing platform

300 to $8 \mu \mathrm{M}$, the color of these solution turns from dark blue to baby blue, the detection limit is reckoned to be $2.24 \mu \mathrm{M}$. When compared with other nanomaterialsbased colorimetric sensing platforms the linear detection range of the constructed sensing platform $\left(\mathrm{F}-\mathrm{MoS}_{2}-\mathrm{FePt}\right.$ TMB- $\mathrm{H}_{2} \mathrm{O}_{2}$ ) is more wide and a lower limit of detection is obtained, as listed in Additional file 1: Table S1 [48, 50, $55,56]$.
To verify the feasibility of the detection of $\mathrm{H}_{2} \mathrm{O}_{2}$ in living cells, the obtained sensing platform is utilized to detect the intracellular $\mathrm{H}_{2} \mathrm{O}_{2}$. To improve the stability in the culture medium, the obtained NCs is modified with SH-PEG-FA. Then the established colorimetric sensing platform is further utilized to detect the intracellular $\mathrm{H}_{2} \mathrm{O}_{2}$ in MCF-7. After 4 h' co-incubation with F-MoS ${ }_{2}-$ FePt-PEG-FA, $0.2 \mathrm{mM}$ TMB and $100 \mu \mathrm{M} \mathrm{H}_{2} \mathrm{O}_{2}$ are added 

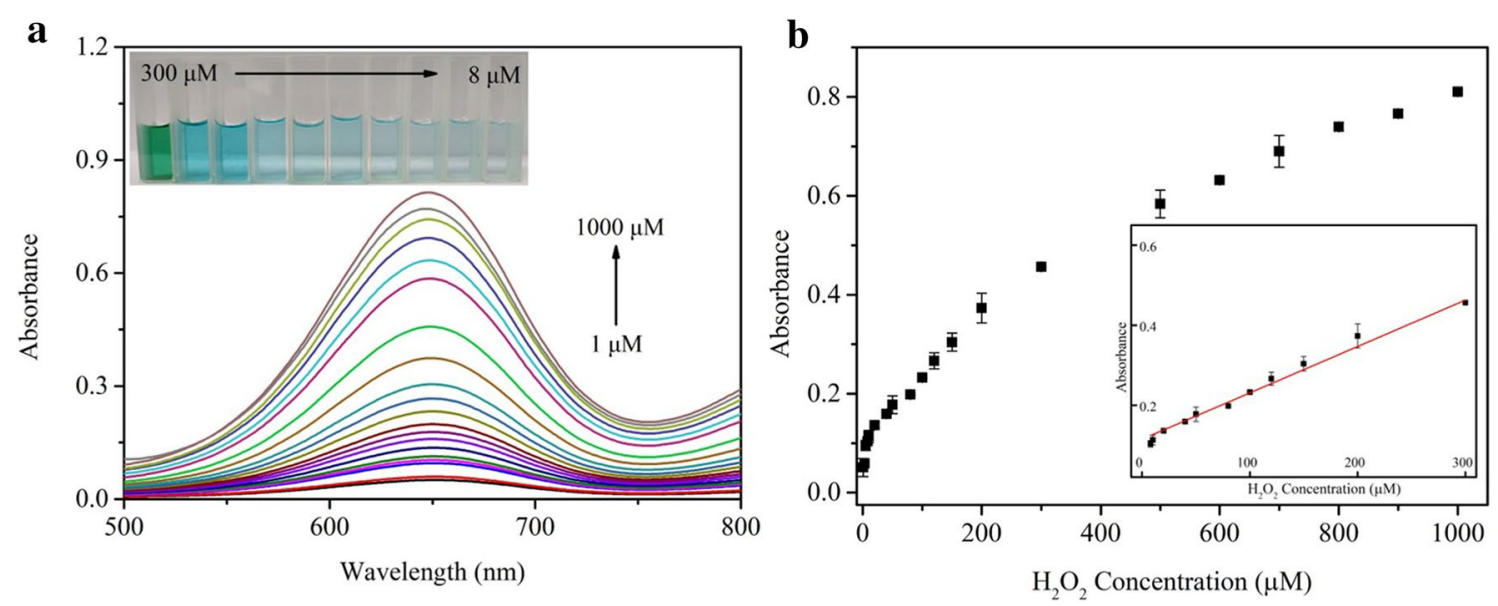

Fig. 8 a The absorption spectra of $\mathrm{H}_{2} \mathrm{O}_{2}$ with various concentration and the corresponding images are shown in the inset picture. These experiments conditions are shown as follows: $1.4 \mathrm{~mL} \mathrm{CPBS} \mathrm{(pH} \mathrm{4.2),} 200 \mu \mathrm{L} \mathrm{TMB} \mathrm{(1} \mathrm{mM),} 200 \mu \mathrm{L} \mathrm{F-MoS}{ }_{2}$-FePt HNPs $\left(20 \mu \mathrm{gL}^{-1}\right)$ and different amount of $\mathrm{H}_{2} \mathrm{O}_{2}$. b Dose-response curve for $\mathrm{H}_{2} \mathrm{O}_{2}$ determination
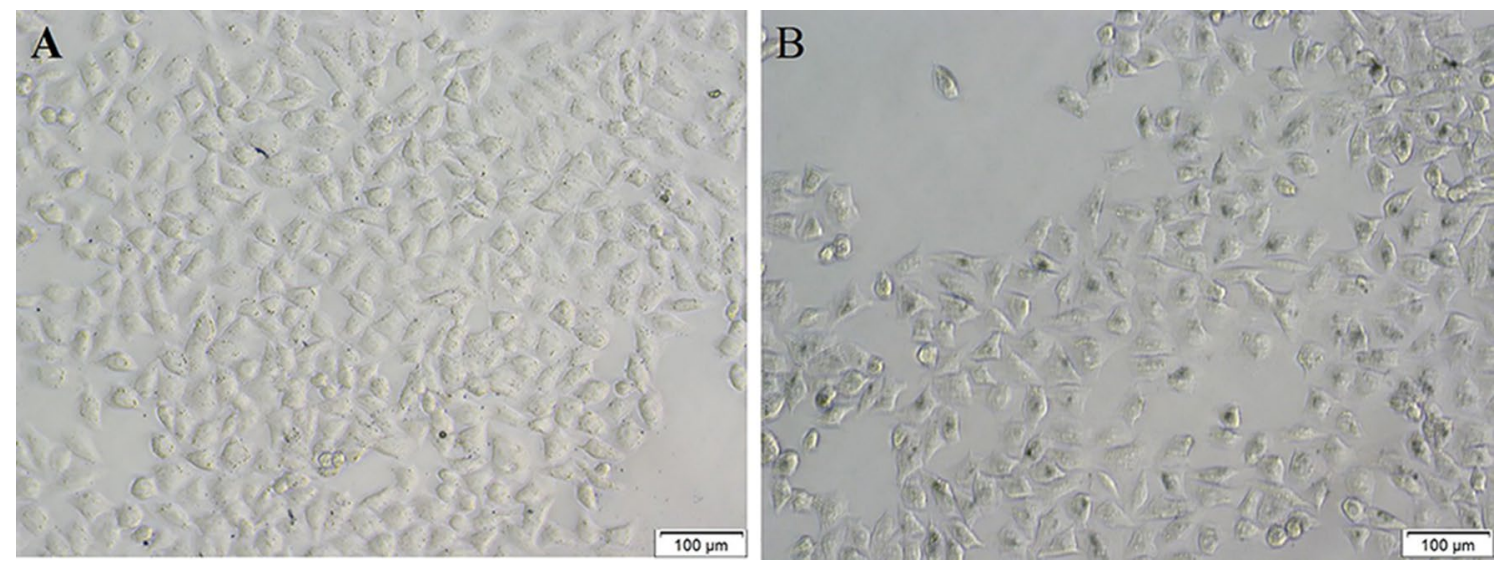

Fig. 9 Images of MCF-7 incubated with F-MoS 2 -FePt-PEG-FA NCs and TMB (A) F-MoS 2 -FePt-PEG-FA and TMB and $\mathrm{H}_{2} \mathrm{O}_{2}$ (B)

into the plate and incubated for another $40 \mathrm{~min}$. After coincubation the cells are subjected to the electron microscope and the images are shown in Fig. 8. Compared with the cells only treated with NCs and TMB (Fig. 9A), the MCF-7 cells treated with NCs, TMB and $\mathrm{H}_{2} \mathrm{O}_{2}$ turn to clear blue (Fig. 9B). Without FA receptor on the cell membrane of normal cell (L02), nearly none NCs can be endocytosed (Additional file 1: Figure S5B). When treated with TMB only, MCF-7 remains colorless, as depicted in Additional file 1: Figure S5 A. The sensitive and selective of intracellular detection indicates that the F-MoS ${ }_{2}$-FePt-PEG-FA have the potential for monitoring of $\mathrm{H}_{2} \mathrm{O}_{2}$ in living cells.

\section{Conclusion}

In this work, a sensitive and rapid colorimetric sensing platform for $\mathrm{H}_{2} \mathrm{O}_{2}$ detection utilizing F-MoS 2 -FePt NCs as artificial enzyme is constructed. The uniformly prepared FePt NPs are anchored on the surface of exfoliated few-layer $\mathrm{MoS}_{2}$ NSs by a facile operation. Series of experiments are carried out to verify the peroxidase-like catalytic activity of the obtained NCs. Under optimal conditions, the linear range of $\mathrm{H}_{2} \mathrm{O}_{2}$ detection is between 8 and $300 \mu \mathrm{M}$ and the detection limit is $2.24 \mu \mathrm{M}$. Compared with other reported methods, $\mathrm{F}-\mathrm{MoS}_{2}$ - $\mathrm{FePt} \mathrm{NCs}$ based colorimetric sensing platform for $\mathrm{H}_{2} \mathrm{O}_{2}$ detection is a sensitive, simple and cost-effective method. To improve the stability and transmembrane performance of F-MoS 2 -FePt NCs, the surface of the prepared NCs is modified by SH-PEG-FA for intracellular $\mathrm{H}_{2} \mathrm{O}_{2}$ detection, which indicates that the sensor could be applied in living 
cells testing and has potential in disease diagnosis and therapy.

\section{Additional file}

Additional file 1: Figure S1. The atomic force microscopy (AFM) images of the as-prepared Few-layers $\mathrm{MoS}_{2}$ nanosheets. Figure S2. The potential distribution of FePt-DMSA NPs. Figure S3. a TEM image of bulk $\mathrm{MoS}_{2}$ sheets; $\mathbf{b}$ HRTEM of $\mathrm{MoS}_{2}$-FePt. Figure S4. Image of FePt NPs before and after transferred from lipophilic to hydrophilic by DMSA via ligand exchange reaction. For the two phases, the upper layer is $n$-hexane, the lower is the water. Figure S5. a Images of MCF-7 cells incubated with TMB (1 mM) and $\mathbf{b} L 02$ cells incubated with F-MoS 2 -FePt-PEG-FA and TMB (1 $\mathrm{mM}$ ). Table $\mathbf{S 1}$. Comparison of the linear range and the detection limit of $\mathrm{H}_{2} \mathrm{O}_{2}$ by means of different sensors.

\section{Authors' contributions}

$\mathrm{ZH}$ performed experiments; $\mathrm{ZD}, \mathrm{XH}, \mathrm{BY}$ and $\mathrm{QL}$ drew the TOC, scheme and figures, $Y Y$ wrote the paper with support from $X Z$. All authors contributed to the general discussion. All authors read and approved the final manuscript.

\section{Author details}

${ }^{1}$ Collage of Chemistry and Molecular Engineering, Qingdao University of Science and Technology, Qingdao, China. ${ }^{2}$ Key Laboratory of Functional Nanomaterials and Technology in Universities of Shandong, Linyi University, Linyi, China. ${ }^{3}$ School of Materials Science and Engineering, Linyi University, Linyi 276000, China. ${ }^{4}$ School of Chemistry and Environmental Engineering, Shandong University of Science and Technology, Qingdao 266510, People's Republic of China.

\section{Acknowledgements}

Financial support from the National Natural Science Foundation of China (Grant Nos.: 21675073, 51872150), Primary Research and Development Plan of Shandong Province (2017GGX20115) and Shandong Province Natural Science Foundation (Nos.: ZR2017BB070, ZR2018MB034) are gratefully acknowledged.

\section{Competing interests}

The authors declare that they have no competing interests.

\section{Availability of data and materials}

All data generated or analyzed during this study are included in the article and Additional file.

\section{Consent for publication}

Not applicable.

\section{Ethics approval and consent to participate}

Not applicable.

Studies involving human participants, human data or human tissue Not applicable.

\section{Publisher's Note}

Springer Nature remains neutral with regard to jurisdictional claims in published maps and institutional affiliations.

\section{Received: 6 September 2018 Accepted: 11 February 2019}

Published online: 13 March 2019

\section{References}

1. Zhu J, Wang S. In situ growth of copper oxide-graphite carbon nitride nanocomposites with peroxidase-mimicking activity for electrocatalytic and colorimetric detection of hydrogen peroxide. Carbon. 2018;129:29-37.

2. Ranji-Burachaloo H, Karimi F, Xie K, Fu Q, Gurr PA, Dunstan DE, Qiao GG. MOF-mediated destruction of cancer using the cell's own hydrogen peroxide. ACS Appl Mater Interfaces. 2017;9:33599-608.

3. Zhan T, Kang J, Li X, Pan L, Li G, Hou W. NiFe layered double hydroxide nanosheets as an efficiently mimic enzyme for colorimetric determination of glucose and $\mathrm{H}_{2} \mathrm{O}_{2}$. Sensor Actuators B Chem. 2018;255:2635-42.

4. Zou J, Shen M, Zhang M, Tu M, Feng R, Yan Y, Zou B. An improved reference method for serum cations measurement by ion chromatography. J Clin Lab Anal. 2018;32:22429-35.

5. Zhang C, Zhang R, Gao X, Cheng C, Hou L, Li X, Chen W. Small naked Pt nanoparticles confined in mesoporous shell of hollow carbon spheres for high-performance nonenzymatic sensing of $\mathrm{H}_{2} \mathrm{O}_{2}$ and glucose. ACS Omega. 2018;3:96-105.

6. Lin X, Ni Y, Kokot S. Electrochemical cholesterol sensor based on cholesterol oxidase and $\mathrm{MoS}_{2}$-AuNPs modified glassy carbon electrode. Sensor Actuators B Chem. 2016;233:100-6.

7. Dutta AK, Das S, Samanta S, Samanta PK, Adhikary B, Biswas P. CuS nanoparticles as a mimic peroxidase for colorimetric estimation of human blood glucose level. Talanta. 2013;107:361-7.

8. Chen Q, Chen H, Li Z, Pang J, Lin T, Guo L, Fu F. Colorimetric sensing of glyphosate in environmental water based on peroxidase mimetic activity of MoS 2 nanosheets. J Nanosci Nanotechnol. 2017;17:5730-4.

9. Wang $\mathrm{Y}$, Zhang D, Wang J. Metastable alpha-AgVO $\mathrm{A}_{3}$ microrods as peroxidase mimetics for colorimetric determination of $\mathrm{H}_{2} \mathrm{O}_{2}$. Mikrochim Acta. 2017;185:1-8.

10. Yang H, Zha J, Zhang P, Xiong Y, Su L, Ye F. Sphere-like CoS with nanostructures as peroxidase mimics for colorimetric determination of $\mathrm{H}_{2} \mathrm{O}_{2}$ and mercury ions. RSC Adv. 2016;6:66963-70.

11. Wei $\mathrm{H}$, Wang $\mathrm{E}$. $\mathrm{Fe}_{3} \mathrm{O}_{4}$ magnetic nanoparticles as peroxidase mimetics and their applications in $\mathrm{H}_{2} \mathrm{O}_{2}$ and glucose detection. Anal Chem. 2008;80:2250-4.

12. Ma Y, Zhang Z, Ren C, Liu G, Chen $X$. $\mathrm{Fe}_{3} \mathrm{O}_{4}$ magnetic nanoparticles as peroxidase mimetics and their applications in $\mathrm{H}_{2} \mathrm{O}_{2}$ and glucose detection. Analyst. 2012;137:485-9.

13. Tang $X Q$, Zhang YD, Jiang ZW, Wang DM, Huang CZ, Li YF. Fe $\mathrm{O}_{4}$ and metal-organic framework MIL-101(Fe) composites catalyze luminol chemiluminescence for sensitively sensing hydrogen peroxide and glucose. Talanta. 2018;179:43-50.

14. Khataee A, Irani-nezhad MH, Hassanzadeh J, Joo SW. Superior peroxidase mimetic activity of tungsten disulfide nanosheets/silver nanoclusters composite: colorimetric, fluorometric and electrochemical studies. J Colloid Interface Sci. 2018;515:39-49.

15. Fu Y, Huang D, Li C, Zou L, Ye B. Graphene blended with $\mathrm{SnO}_{2}$ and Pd-Pt nanocages for sensitive non-enzymatic electrochemical detection of $\mathrm{H}_{2} \mathrm{O}_{2}$ released from living cells. Anal Chim Acta. 2018;1014:10-8.

16. Lin $L$, Song $X$, Chen $Y$, Rong $M$, Zhao $T$, Wang $Y$, Jiang $Y$, Chen $X$. Intrinsic peroxidase-like catalytic activity of nitrogen-doped graphene quantum dots and their application in the colorimetric detection of $\mathrm{H}_{2} \mathrm{O}_{2}$ and glucose. Anal Chim Acta. 2015;869:89-95.

17. Shi L, Layani M, Cai X, Zhao H, Magdassi S, Lan M. An inkjet printed Ag electrode fabricated on plastic substrate with a chemical sintering approach for the electrochemical sensing of hydrogen peroxide. Sensor Actuators B Chem. 2018;256:938-45.

18. Jin L, Meng Z, Zhang Y, Cai S, Zhang Z, Li C, Shang L, Shen Y. Ultrasmall Pt nanoclusters as robust peroxidase mimics for colorimetric detection of glucose in human serum. ACS Appl Mater Interfaces. 2017;9:10027-33.

19. Singh VK, Yadav PK, Chandra S, Bano D, Talat M, Hasan SH. Peroxidase mimetic activity of fluorescent NS-carbon quantum dots and its application for colorimetric detection of $\mathrm{H}_{2} \mathrm{O}_{2}$ and glutathione in human blood serum. J Mater Chem B. 2018;42:6803-9.

20. Yang Q, Lu S, Shen B, Bao S, Liu Y. An iron hydroxyl phosphate microoctahedron catalyst as an efficient peroxidase mimic for sensitive and colorimetric quantification of $\mathrm{H}_{2} \mathrm{O}_{2}$ and glucose. New J Chem. 2018;42:6803-9.

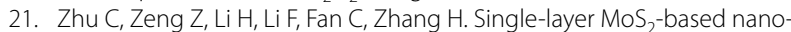
probes for homogeneous detection of biomolecules. J Am Chem Soc. 2013;135:5998-6001.

22. Zhao K, Gu W, Zheng S, Zhang C, Xian Y. SDS-MoS 2 nanoparticles as highly-efficient peroxidase mimetics for colorimetric detection of $\mathrm{H}_{2} \mathrm{O}_{2}$ and glucose. Talanta. 2015;141:47-52. 
23. Wang $R$, Jin D, Zhang $Y$, Wang $S$, Lang J, Yan $X$, Zhang L. Engineering metal organic framework derived 3D nanostructures for high performance hybrid supercapacitors. J Mater Chem A. 2017;5:292-302.

24. Yin W, Yu J, LV F, Yan L, Zheng LR, Gu Z, Zhao Y. Functionalized nano-MoS with peroxidase catalytic and near-infrared photothermal activities for safe and synergetic wound antibacterial applications. ACS Nano. 2016;10:11000-11.

25. Meng X, Liu Z, Cao Y, Dai W, Zhang K, Dong H, Feng X, Zhang X. Fabricating aptamer-conjugated PEGylated-MoS $/ \mathrm{Cu}_{1.8} \mathrm{~S}$ theranostic nanoplatform for multiplexed imaging diagnosis and chemo-photothermal therapy of cancer. Adv Funct Mater. 2017;27:1605592.

26. Zhou W, Yin Z, Du Y, Huang X, Zeng Z, Fan Z, Liu H, Wang J, Zhang H. Synthesis of few-layer $\mathrm{MoS}_{2}$ nanosheet-coated $\mathrm{TiO}_{2}$ nanobelt heterostructures for enhanced photocatalytic activities. Small. 2013;9:140-7.

27. Cai S, Han Q, Qi C, Wang X, Wang T, Jia X, Yang R, Wang C. MoS $-\mathrm{St}_{3} \mathrm{Au}_{1}$ nanocomposites with enhanced peroxidase-like activities for selective colorimetric detection of phenol. Chin J Chem. 2017;35:605-12.

28. Zhu D, Liu W, Zhao D, Hao Q, Li J, Huang J, Shi J, Chao J, Su S, Wang L. Label-free electrochemical sensing platform for microRNA-21 detection using thionine and gold nanoparticles co-functionalized $\mathrm{MoS}_{2}$ nanosheet. ACS Appl Mater Interfaces. 2017;41:35597-603.

29. Wu X, Yan X, Dai Y, Wang J, Wang J, Cheng X. Facile synthesis of AgNPs/ $\mathrm{MoS}_{2}$ nanocomposite with excellent electrochemical properties. Mater Lett. 2015;152:128-30.

30. Zu S, Li B, Gong Y, Li Z, Ajayan PM, Fang Z. Active control of plasmonexciton coupling in $\mathrm{MoS}_{2}$-Ag hybrid nanostructures. Adv Opt Mater. 2016:4:1463-9.

31. Yuwen L, Xu F, Xue B, Luo Z, Zhang Q, Bao B, Su S, Weng L, Huang W, Wang L. General synthesis of noble metal (Au, Ag, Pd, Pt) nanocrystal modified $\mathrm{MoS}_{2}$ nanosheets and the enhanced catalytic activity of Pd$\mathrm{MoS}_{2}$ for methanol oxidation. Nanoscale. 2014;6:5762-9.

32. Su S, Zou M, Zhao H, Yuan C, XU Y, Zhang C, Wang L, Fan C, Wang L. Shape-controlled gold nanoparticles supported on $\mathrm{MoS}_{2}$ nanosheets: synergistic effect of thionine and $\mathrm{MoS}_{2}$ and its application for electrochemical label-free immunosensing. Nanoscale. 2015;7:19129-35.

33. Nirala NR, Prakash R. One step synthesis of AuNPs@MoS 2 -QDs composite as a robust peroxidase- mimetic for instant unaided eye detection of glucose in serum, saliva and tear. Sens Actuators B Chem. 2018;263:109-19.

34. Zhu Z, Yin H, He CT, Al-Mamun M, Liu P, Jiang L, Zhao Y, Wang Y, Yang HG, Tang Z, Wang D, Chen XM, Zhao H. Ultrathin transition metal dichalcogenide/3d metal hydroxide hybridized nanosheets to enhance hydrogen evolution activity. Adv Mater. 2018;30:1801171.

35. Liu W, Ding F, Wang Y, Mao L, Liang R, Zou P, Wang X, Zhao Q, Rao H. Fluorometric and colorimetric sensor array for discrimination of glucose using enzymatic-triggered dual-signal system consisting of Au@Ag nanoparticles and carbon nanodots. Sensor Actuators B Chem. 2018;265:310-7.

36. Liu W, Hiekel K, Hübner R, Sun H, Ferancova A, Sillanpää M. Pt and Au bimetallic and monometallic nanostructured amperometric sensors for direct detection of hydrogen peroxide: influences of bimetallic effect and silica support. Sens Actuators B Chem. 2018;255:1325-34.

37. Chen Q, Lin T, Huang J, Chen Y, Guo L, Fu F. Colorimetric detection of residual hydrogen peroxide in soaked food based on Au@Ag nanorods. Anal Methods. 2018;10:504-7.

38. Bai Z, Dong W, Ren Y, Zhang C, Chen Q. Preparation of nano Au and Pt alloy microspheres decorated with reduced graphene oxide for nonenzymatic hydrogen peroxide sensing. Langmuir. 2018;34:2235-44.

39. Cai S, Jia X, Han Q, Yan X, Yang R, Wang C. Porous Pt/Ag nanoparticles with excellent multifunctional enzyme mimic activities and antibacterial effects. Nano Res. 2017;10:2056-69.

40. Zhang XZ, Zhou Y, Zhang W, Zhang Y, Gu N. Polystyrene@Au@prussian blue nanocomposites with enzyme-like activity and their application in glucose detection. Colloids Surf A. 2016;490:291-9.

41. Liu H, Jiao M, Gu C, Zhang M. Au@CuxO solk-shell nanomaterials with porous shells act as a new peroxidase mimic for the colorimetric detection of $\mathrm{H}_{2} \mathrm{O}_{2}$. J Alloys Compd. 2018;741:197-204.
42. Yin W, Yan L, Yu J, Tian G, Zhou L, Zheng X, Zhang X, Yong Y, Li J, Gu Z, Zhao $Y$. High-throughput synthesis of single-layer $\mathrm{MoS}_{2}$ nanosheets as a near-infrared photothermal-triggered drug delivery for effective cancer therapy. ACS Nano. 2014;20:6922-33.

43. Wang C, Hou Y, Kim J, Sun S. A general strategy for synthesizing FePt nanowires and nanorods. Angew Chem Int Ed. 2007;46:6333-5.

44. Chen M, Liu JP, Sun S. One-step synthesis of FePt nanoparticles with tunable size. J Am Chem Soc. 2004;126:8394-5.

45. Kim J, Lee Y, Sun S. Structurally ordered FePt nanoparticles and their enhanced catalysis for oxygen reduction reaction. J Am Chem Soc. 2010;132:4996-7.

46. Xing $M$, Xu W, Dong C, Bai Y, Zeng J, Zhou Y, Zhang J, Yin Y. Metal sulfides as excellent $\mathrm{Co}$-catalysts for $\mathrm{H}_{2} \mathrm{O}_{2}$ decomposition in advanced oxidation processes. Chem. 2018;4:1359-72.

47. Chen X, Su B, Cai Z, Chen X, Oyama M. PtPd nanodendrites supported on graphene nanosheets: a peroxidase-like catalyst for colorimetric detection of $\mathrm{H}_{2} \mathrm{O}_{2}$. Sens Actuators B Chem. 2014;201:286-92.

48. Cai S, Han Q, Qi C, Lian Z, Jia X, Yang R, Wang C. Pt ${ }_{74} \mathrm{Ag}_{26}$ nanoparticlesdecorated ultrathin $\mathrm{MoS}_{2}$ nanosheets as novel peroxidase mimics for highly selective colorimetric detection of $\mathrm{H}_{2} \mathrm{O}_{2}$ and glucose. Nanoscale. 2016;8:3685-94.

49. Liu F, He J, Zeng M, Hao J, Guo Q, Song Y, Wang L. Cu-hemin metalorganic frameworks with peroxidase-like activity as peroxidase mimics for colorimetric sensing of glucose. J Nanopart Res. 2016;18:106-14.

50. Wang N, Sun J, Chen L, Fan $\mathrm{H}, \mathrm{Ai} \mathrm{S}$. A C $\mathrm{Cu}_{2}(\mathrm{OH})_{3} \mathrm{Cl}_{-}-\mathrm{CeO}_{2}$ nanocomposite with peroxidase-like activity, and its application to the determination of hydrogen peroxide, glucose and cholesterol. Microchim Acta. 2015;182:1733-8.

51. Wang Q, Zhang L, Shang C, Zhang Z, Dong S. Triple-enzyme mimetic activity of nickel-palladium hollow nanoparticles and their application in colorimetric biosensing of glucose. Chem Commun (Camb). 2016;52:5410-3.

52. $\mathrm{Mu}$ J, Zhang $\mathrm{L}$, Zhao $\mathrm{M}$, Wang $\mathrm{Y}$. Catalase mimic property of $\mathrm{CO}_{3} \mathrm{O}_{4}$ nanomaterials with different morphology and its application as a calcium sensor. ACS Appl Mater Interfaces. 2014;6:7090-8.

53. Ding Y, Yang B, Liu H, Liu Z, Zhang X, Zheng X, Liu Q. FePt-Au ternary metallic nanoparticles with the enhanced peroxidase-like activity for ultrafast colorimetric detection of $\mathrm{H}_{2} \mathrm{O}_{2}$. Sens Actuators $\mathrm{B}$ Chem. 2018;259:775-83.

54. Zhu L, Gao F, Ge J. N,N'-di-caboxy methyl perylene diimides functionalized magnetic nanocomposites with enhanced peroxidase-like activity for colorimetric sensor of $\mathrm{H}_{2} \mathrm{O}_{2}$ and glucose. Sens Actuators $\mathrm{B}$ Chem. 2016;41:5853-62.

55. Liu H, Ding Y, Yang B, Liu Z, Liu Q, Zhang X. Colorimetric and ultrasensitive detection of $\mathrm{H}_{2} \mathrm{O}_{2}$ based on $\mathrm{Au} / \mathrm{CO}_{3} \mathrm{O}_{4}-\mathrm{CeO}$ nanocomposites with enhanced peroxidase-like performance. Sens Actuators B Chem. 2018;271:336-45

56. Liu $Q$, Yang $Y, L v X$, Ding $Y$, Zhang $Y$, Jing J, Xu C. One-step synthesis of uniform nanoparticles of porphyrin functionalized ceria with promising peroxidase mimetics for $\mathrm{H}_{2} \mathrm{O}_{2}$ and glucose colorimetric detection. Sens Actuators B Chem. 2017;240:726-34.

Ready to submit your research? Choose BMC and benefit from:

- fast, convenient online submission

- thorough peer review by experienced researchers in your field

- rapid publication on acceptance

- support for research data, including large and complex data types

- gold Open Access which fosters wider collaboration and increased citations

- maximum visibility for your research: over 100M website views per year

At BMC, research is always in progress.

Learn more biomedcentral.com/submissions 